\title{
Numerical simulation and experimental validation of solar greenhouse dryer using finite element analysis for different roof shapes
}

Aditya Arvind YADAV, Pravin A. PRABHU, Jaydeep S. BAGI

DOI: 10.30464/jmee.2021.5.1.69

Cite this article as:

Yadav A. A., Prabhu P. A., Bagi J. S. Numerical simulation and experimental validation of solar greenhouse dryer using finite element analysis for different roof shapes. Journal of Mechanical and Energy Engineering, Vol. 5(45), No. 1, 2021, pp. 69-80.

\section{VOLUME 5(45) | No. 1 | MARCH 2021}

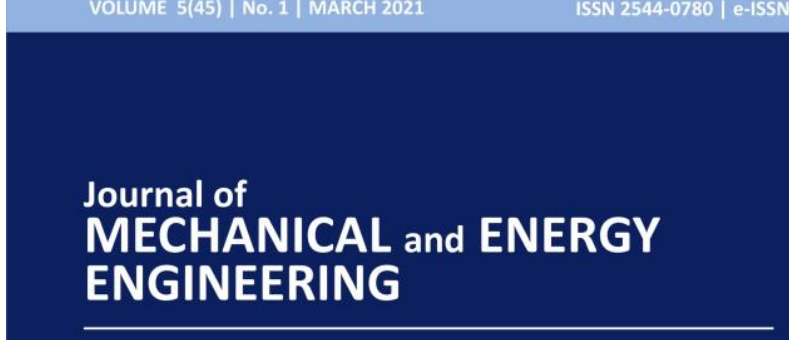

\section{Editor-in-Chief}

Waldemar Kuczyński

Editors

Krzysztof Nadolny
Journal of Mechanical and Energy

Engineering

Website: jmee.tu.koszalin.pl

ISSN (Print): 2544-0780

ISSN (Online): 2544-1671

Volume: 5(45)

Number: 1

Year: 2021

Pages: 69-80

\section{Article Info:}

Received 22 January 2021

Accepted 4 February 2021

\section{Open Access}

This article is distributed under the terms of the Creative Commons Attribution 4.0 (CC BY 4.0) International License (http://creativecommons.org/licenses/by/4.0/), which permits unrestricted use, distribution, and reproduction in any medium, provided you give appropriate credit to the original author(s) and the source, provide a link to the Creative Commons license, and indicate if changes were made. 


\title{
NUMERICAL SIMULATION AND EXPERIMENTAL VALIDATION OF SOLAR GREENHOUSE DRYER USING FINITE ELEMENT ANALYSIS FOR DIFFERENT ROOF SHAPES
}

\author{
Aditya Arvind YADAV ${ }^{*}$, Pravin A. PRABHU ${ }^{2}$, Jaydeep S. BAGI ${ }^{3}$ \\ ${ }^{1 *} \mathrm{M}$. Tech (Energy Technology), ${ }^{2}$ Co-ordinator M. Tech (Energy Technology), ${ }^{3}$ Director. \\ Department of Technology, Shivaji University, Kolhapur, Maharashtra State., India \\ Corresponding Author e-mail: adiyadav821@gmail.com
}

(Received 22 January 2021, Accepted 4 February 2021)

\begin{abstract}
The present study focuses on the numerical simulation and experimental validation of a Solar Greenhouse Dryer (SGHD). The Solar Dryers are the devices which uses solar energy to dry substances, especially crops with high moisture content, and the word Greenhouse means protection of crops from excess hot or cold climatic conditions and unwanted pests. Thus, Solar Greenhouse Dryer is a device which utilizes solar energy for drying of crops with high moisture content and prevents it from excess climatic conditions and provides optimum range of temperature and prevents the dried product from pests and dust while drying. The numerical simulation of SGHD was performed using Finite Element Analysis software ANSYS 2020 R2. Initially three different roof shapes were modelled using software CATIA V5 R3 namely triangular, trapezoidal and dome shape. The modelled SGHDs was then introduced to ANSYS domain for numerical analysis. The models were initially meshed in ANSYS workbench with unstructured tetrahedral structure of mesh over all the domains. The Solar Ray tracing content was used for numerical simulation of dryers, the solar ray tracing is used to predict direct illumination energy source produced by sun at experimental site. The experiment for no-load test was conducted at Bahe Borgaon, Dist- Sangli, Maharashtra, India at $17.115^{\circ} \mathrm{N}$ and $74.33^{\circ} \mathrm{E}$.
\end{abstract}

Keywords: solar greenhouse dryer, drying, moisture removal, solar thermal energy, finite element analysis

\section{INTRODUCTION}

The solar drying technique is one of the oldest and traditional techniques used for the post-harvesting of crops, vegetables, and fruits. The main purpose of the drying process is to reduce or release the moisture of the crop to avoid further loss due to excess microorganisms' growth. Traditionally open sun drying was implemented as the drying process for crops in many countries as a sufficiently large area of land is easily available. The open sun drying affects the flavor, texture, and color of the dried product as the temperature goes beyond a certain limit. Therefore, controlled drying is one of the advanced techniques that is used for drying crops under adequate temperature conditions to avoid flavor, texture, and color losses during the drying process. The loss during the open sun drying is sometimes unrecoverable. The texture of the dried products affects the taste of the product.

The atmospheric conditions also affect the open sun drying phenomenon. The uneven change in the climate, uneven rainfall, uneven winds affect the dried products to a greater extent. The quality and quantity of the final drier products affect due to such uneven climatic conditions. The actual working of open sun drying is that the dried product is laid under the solar radiation for drying. The solar energy incident onto the dried product heats the product and finally releases the moisture content into the dry adjacent air thereby reducing the moisture of the dried product. The drying process is very useful in the agricultural context as it lowers post-harvest crop losses. It has been estimated that nearly $10 \%$ to $40 \%$ of the crops harvested every year face the problem of post-harvest losses [1]. 
Many underdeveloped countries face the problem of post-harvest losses of agricultural products due to the lack of removal of moisture from the agricultural yield. It is estimated that nearly $40 \%$ of the produced agricultural yield, in India faces post-harvest loss each year. According to the National Academy of Sciences, India (NAS, India), Indian farmers incur loss of Rs 92,651 crore per year due to post-harvest loss due to lack of storage and transportation facilities. The major reason for this is post-harvest losses are high moisture content in agricultural yield. The high moisture content in agricultural yield further results in fungal and microbial degradation in agricultural yields. This microbial degradation in the agricultural yield starts shortly after the agricultural yield is harvested. The microbial degradation starts at the place where the moisture content in the agricultural yield is higher. This microbial degradation commences and spreads over the agricultural yield where the moisture content is comparatively lower than the surrounding area. In rural areas due to lack of electricity and other drying equipment's the agricultural yield leads to excess microbial degradation. This microbial degradation and loss of the agricultural yield should be prevented to have a proper and optimum food security level in the nation. The balance between the agricultural yield and the post-harvest loss due to microbial decomposition should be maintained [1].

The high moisture content in the agricultural yield results in the development of microorganisms. The production of microorganisms takes place in agricultural yield where the moisture content is comparatively higher than the atmospheric moisture content. The other degradation or deterioration of agricultural yield are mechanical injuries during the post-harvest method, ethylene production, pathological breakdown, sprouting, etc. This deterioration further gives rise to loss of flavor, color, and texture loss. The loss of food due to biological degradation mainly depends upon the parameters like temperature, air velocity, atmospheric condition, and relative humidity respectively. Thus, to avoid all the losses, the drying process is the most promising technique that preserves the agricultural yield and improves the shelf life of the product, reducing the weight and volume of the dried product respectively [1].

The drying process can be defined as the process of removal of excess moisture content from the fresh agricultural yield. Thus, normal drying is the process in which the agricultural yield is placed in an open atmosphere under solar insolation. The heat absorbed by the solar insolation evaporates the moisture content and the air flows in the atmosphere to remove the water vapor respectively. The first step in the drying process is the water present at the surface the agricultural yield is evaporated due to solar insolation. The heat absorbed by the product is such that the water content present inside the product migrates to the surface. The physical water present on the surface of the product is only removed during the drying process whereas the chemically bonded water or moisture content is not removed during the drying process.

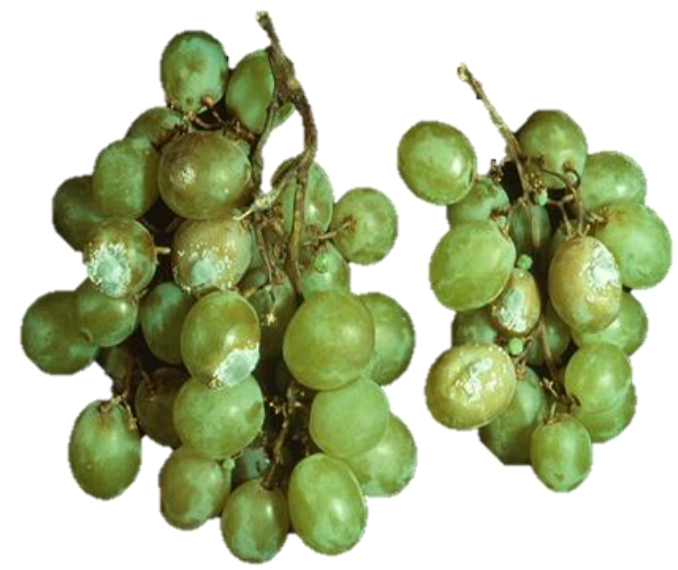

Fig. 1. Biological Degradation of grapes

Thus, the main objective of the solar dryer is to provide an optimum temperature for the drying process than the ambient atmospheric condition. As the temperature of the solar dryer is increased the saturation pressure above the dried product is increased subsequently, the saturation pressure is the function of temperature for a pure substance. The saturation pressure is the pressure at which solid and vapour both exists in equilibrium condition. The increase in temperature increases the vapour present on the dried surface and so increases the saturated vapour pressure. The relative humidity is the amount of water vapour present in the air, it is the measure of moisture in the air. The vapour pressure is directly proportional to the relative humidity and vice versa Thus, the entire drying process agricultural yield is completely dependent on the product size, shape, and initial moisture content respectively [2].

The higher moisture content results in excess spoilage of the food products. The moisture content in the food products can be found in either of the two forms:

- free water,

- bound moisture.

The free water takes part in the chemical reactions and biological processes which are mainly responsible for the spoilage of food products. The free water takes part in enzymatic and non-enzymatic reactions, spore germinations, and the growth of microorganisms. This rate of growth of microorganisms can be reduced by maintaining the moisture content between 0.6 on a scale. The water activity $\left(a_{w}\right)$ in a food product can be defined as the ratio of the pressure of water vapor just 
above the wet product to that of partial pressure of pure water at the same temperature.

$$
\text { Water activity }\left(a_{w}\right)=P / P o=E R H / 100
$$

where: $P$ partial pressure of water vapor over wet product; $P o$ partial pressure of pure water at saturation and the same temperature; ERH Equilibrium Relative Humidity.

The water activity $\left(a_{w}\right)$ can be represented on a scale of 0 to 1 . The details of the reaction rate to the water activity $\left(a_{w}\right)$ are represented in the graph below.

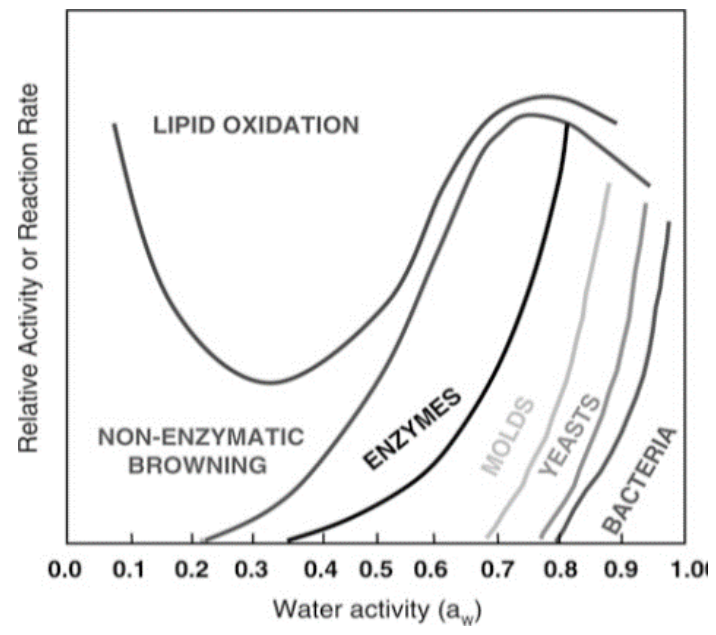

Fig. 2. The reaction rate to water activity $\left(a_{w}\right)$ graph

The range from 0.95 to 1 affects the growth of pseudomonas, bacillus Escherichia and yeast formation on a food product. The range from 0.91 to 0.95 affects the growth of salmonella, vibrio, molds, and yeasts. The range from 0.87 to 0.91 affects the growth of yeasts. The range from 0.80 to 0.87 affects the growth of molds. The range from 0.80 to 0.65 affects the growth of various halophilic bacteria, Xerophilic molds, and Osmophilic yeasts. Whereas the range below 0.65 has no microbial prefiltration [2].

The significant areas in the above curve are lipid oxidation, enzymatic browning, and non-enzymatic browning respectively. The lipid is an organic compound that consists of fatty acids and their derivatives which are insoluble in water but are soluble in various organic solvents. Lipid oxidation or autooxidation is the reaction between oxygen and unsaturated lipids to form lipid hydro-peroxide. The entire reaction is divided into three stages free radical mechanism which is as follows.

1. Initiation. The initiation step is the formation of lipid-free radicals through catalysis agents like heat, metal ions, and irradiation. This free radical reacts with oxygen to form peroxy radicals.

2. Propagation. The peroxy free radical further combines with a lipid molecule to form hydroperoxide and a new free radical.
3. Termination. The free radicals formed during the propagation step, combine to form non-free radicals.

The reaction of lipid oxidation continues until depletion of oxygen, fatty radical reacts with stable antioxidant radicals and two unstable radicals react together i.e. termination process.

The browning reactions can be studied with the help of oxidative enzymatic browning, caramelization, and non-oxidative or non-enzymatic browning respectively. The oxidative enzymatic browning comprises of action of a set of enzymes. In this reaction Polyphenol Oxidase (PPO) or Phenolase present in the food product reacts in the presence of oxygen to form a brown color on the food, turning the original color into a brownish shade. Generally, oxidative enzymatic browning is observed in apples when they are sliced and placed in an open atmosphere.

Caramelization is the reaction of carbohydrates present in the food product. It comprises a set of reactions that are the outcome of direct heating of carbohydrate or principally sugar in a food product. The sucrose present in food products consists of glucose and fructose in presence of heat converts into acetic acid which offers a salty taste, maltol which offers a caramel taste, and furan which offers a nutty taste respectively. The caramelization reaction results in the development of flavor, darkening, and formation of color in the mixture in the food product.

The non-oxidative or non-enzymatic browning can be studied with the help of Millard's reaction. In this reaction, there is no involvement of oxygen or any kind of enzyme. The sugars, amino acids, and other nitrogenous bases present in food products combine in presence of heat to form N-Glycosides, which adds new flavor and new color to the food product.

Therefore, there is a need for an optimum temperature of the drying phenomenon. As the lower temperature for drying will enhance the growth of micro-organisms and the higher temperature will give rise to the case hardening process respectively.

Thus, the main aim of the present research work is to design and develop a Solar Modified Greenhouse model for drying various seasonal grains, fruits, and vegetables by analyzing various designs for roofs and finding an optimum roof shape for Solar Greenhouse Dryer. The drying process increases the shelf life of the product inducing the dried product its original flavor, texture, and color respectively. The main aim of the numerical simulation is to provide a benchmark for manufacturing of the solar greenhouse dryer and its temperature distribution at various sections.

The word greenhouse dryer is used for a building that is highly glazed with thermal conditioning for desired range and it is used for cultivating crops, plants, vegetables, etc. The actual working of a greenhouse is that the short-wave radiations falling on the greenhouse 
are absorbed by the outer glazing material thereby heating the interior area of the greenhouse and providing ambient heat for plants, vegetable growth respectively. The heated space is retained within the enclosure of the greenhouse. This phenomenon is called the greenhouse effect. The important role played during the greenhouse effect phenomenon are the atmosphere, insulating roofs, walls, etc.

When the solar radiation enters the surface of the greenhouse some part of the solar radiation is absorbed by the earth's surface whereas some part of the radiation is thrown back also called infrared radiations. This infrared radiation emitted by the surface of the earth is then absorbed by various gases like $\mathrm{CO}_{2}$, methane, NOx, and water vapor. This absorption of the infrared radiation by the atmosphere and various gases like $\mathrm{CO}_{2}$, methane, $\mathrm{NOx}$, and water vapor is called the greenhouse effect. The greenhouse effect helps in maintaining the temperature of the earth at ambient temperature, without the greenhouse effect the earth's temperature would have been $-18^{\circ} \mathrm{C}$ respectively [3].

The various parameters considered during the designing of the solar greenhouse dryer are as follows.

1. Glazing Materials. The proper glazing materials allow maximum solar radiation to enter into greenhouse dryer. The heat loss from the glazing material should be minimum as possible. The absorptivity is the measure of radiations absorbed; whereas reflexivity is the measure of radiations reflected; and transmissivity is the measure of radiations passes through object. Thus, to maintain the greenhouse effect in dryer, the glazing material should have maximum absorptivity and minimum reflexivity and transmissivity. The thin transparent polyethene plastic foil with a thickness of $200 \mu \mathrm{m}$ absorbs direct and diffuse solar radiation.

2. Ventilation methods. The ventilation methods can be divided into free and forced ventilation. The free ventilation can be effectively used for solar drying as there is a lack of electricity in rural areas.

3. Solar Orientation. The Solar Greenhouse Dryer should be south-oriented to gain maximum solar radiation. As the India lies in Northern hemisphere with coordinates of India are $20.59^{\circ} \mathrm{N}$ and $78.96^{\circ} \mathrm{E}$. Therefore, the roof inclination should have a $23^{\circ}$ to $25^{\circ}$ roof angle to gain $90 \%$ of solar radiation. The north wall of the Solar Greenhouse Dryer is well insulated to avoid heat loss [4].

\section{MATERIALS AND METHODS}

The modeling of the Solar Greenhouse Dryer for various roof shapes was done using CATIA V5 R20. The numerical simulation for temperature distribution was done using ANSYS 2020 R2 Academic. The total shapes considered for analysis were three namely triangular roofs, trapezoidal roofs, and dome-shaped roofs respectively.

The dimensions of the Computational domain i.e., Solar Greenhouse Dryer was based on the experimental work. The dimensions of the Solar Greenhouse Dryer were as follows (Tab. 1).

Tab. 1. Dimensions of CAD Model

\begin{tabular}{ccc}
\hline Sr. no. & Specifications & Details, $\mathrm{mm}$ \\
\hline 1 & Length & 1000 \\
\hline 2 & $\begin{array}{c}\text { Height of lower } \\
\text { rectangluar frame }\end{array}$ & 500 \\
\hline 3 & $\begin{array}{c}\text { Height from lower } \\
\text { rectangular frame to } \\
\text { apex }\end{array}$ & 400 \\
\hline 4 & Width & 600 \\
\hline
\end{tabular}

The steps involved in numerical simulation of SGHD is as follows:

1. Initially the three different shapes of SGHDs were modelled in CATIA V5 R20, during the modelling the structure was considered hollows so as to allow the boundary conditions and air properties in hollow section.

2. The modelled structures were then imported to ANSYS Workbench for numerical simulation.

3. After the modelled structures were imported to ANSYS Workbench, the meshing of structures was done. The meshing selected was unstructured tetrahedral.

4. The number of nodes and elements after meshing for triangular roof design was 5735 and 23110, for dome roof design it was 5957 and 24299; and for trapezoidal roof design it was 6099 and 25291 respectively.

5. The viscous model selected during numerical simulation was k-epsilon i.e., it consists of two equations.

The details of K-epsilon turbulence model is as follows.

The K-epsilon model is used to simulate the flow characteristics i.e., turbulent flow characteristics. As the air flowing over solar dryer is turbulent. Hence it is used during numerical simulation. The K-epsilon model is basically a two-equation model that is used basically for turbulent flow of fluid over a model.

The actual equations used during numerical simulation contains many unknown and unmeasurable terms. In standard K-epsilon method the main aim is to minimize those unknown values. The standard K-epsilon model can be given in two set of equations namely, turbulent kinetic energy equation and dissipation equation respectively.

The details of both the equation is as given below:

Turbulent Kinetic Energy Equation $(k)$ :

$\frac{\partial(\rho k)}{\partial t}+\frac{\partial(\rho k u i)}{\partial x i}=\frac{\partial}{\partial x j}\left[\frac{u t}{\sigma k} \frac{\delta k}{\delta x j}\right]+2 \mu E i j E i j-\rho \varepsilon$. 
Dissipation equation:

$$
\begin{gathered}
\frac{\delta(\rho \varepsilon)}{\delta t}+\frac{\delta(\rho \varepsilon \mu i)}{\delta x i}=\frac{\delta}{\delta x j}\left[\frac{\mu t}{\sigma \epsilon} \frac{\delta \varepsilon}{\delta x j}\right]+ \\
C 1 \varepsilon \frac{\varepsilon}{k} 2 \mu t E i j E i j-C 2 \varepsilon \rho \frac{\varepsilon 2}{k},
\end{gathered}
$$

where; $\mu=$ velocity component in corresponding direction, $E i j=$ Rate of deformation, $\mu \mathrm{t}=$ Eddy viscosity.

1. After the turbulence model was set, the realizable settings were provided for turbulence model.

2. The enhanced wall treatment was provided in viscous model during numerical simulation.

3. The model constants consists of C2-Epsilon with a value of 1.9, TKE Prandtl Number equals to 1; TDR Prandtl Number equals to 1.2; Energy Prandtl Number equals to 0.85; and wall Prandtl Number equals to 0.85 were set during numerical simulation.

4. As the solar dryer receives solar radiations, another model selected during numerical simulation was radiation model. As the optical thickness of models were greater than 3, therefore the Rosseland radiation model theory was selected during numerical simulation.

The details of Rosseland Radiation Model are as follow.

The Roseland Radiation Model also known as diffusion approximation is used for problems where the optical thickness is greater than 3. In Rosseland Radiation Model the intensity of radiation is the intensity at the gas temperature, As in P-1 Model, the radiative heat flux can be given by equation:

$$
q r=-\top \nabla G
$$

Now substituting the value of $\mathrm{G}=4 \sigma n^{2} T^{4}$ in above equation:

$$
q r=-16 \sigma 7 n^{2} T^{3} \nabla T .
$$

From the Fourier's conduction law, the above equation can also be written as:

$$
\begin{gathered}
q=q c+q r=-(k+k r) \nabla \mathrm{T}, \\
k r=16 \sigma\urcorner n^{2} T^{3},
\end{gathered}
$$

where: $k=$ thermal conductivity, $k r=$ radiative conductivity.

5. After the Rosseland model was selected, the solar load model selected was Solar Ray Tracing. The details of solar load model are as follows. The Solar Load model is used to calculate the radiation effect on the computational domain with the help of sun rays. The solar ray tracing model is algorithm-based model that uses direct illuminating energy from sun. It takes beam as an illuminating energy from sun at desired location. The beam is then incident on the computational domain i.e., walls of dryer inlet and outlet. The shading analysis is also done as per boundary conditions, and the heat flux has been generated on the boundary faces of the computational domain.

The heat flux is that has been computed by solar ray tracing algorithm is coupled to the ANSYS Workbench with the help of energy equation. The total time steps per solar load selected was 10 . The sun direction vector selected during simulation was in $\mathrm{x}$ - coordinate it was -0.580 ; $\mathrm{y}$-coordinate it was 0.378 and in $\mathrm{z}$ coordinate it was 0.720 respectively. The direct solar radiation and diffuse soar radiation both were considered during numerical simulation.

6. At last, the solution method selected was pressurevelocity coupling.

The spatial discretization gradient selected was gauss-gauss node-based method. The high order term relaxation was set during numerical simulation respectively.

The details of the CAD Model are as elaborated in Figures 3 to 5 .

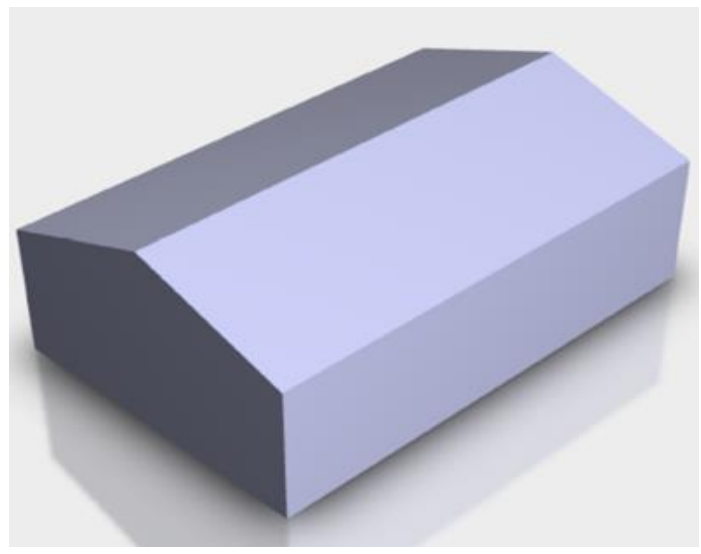

Fig. 3. Triangular roof design

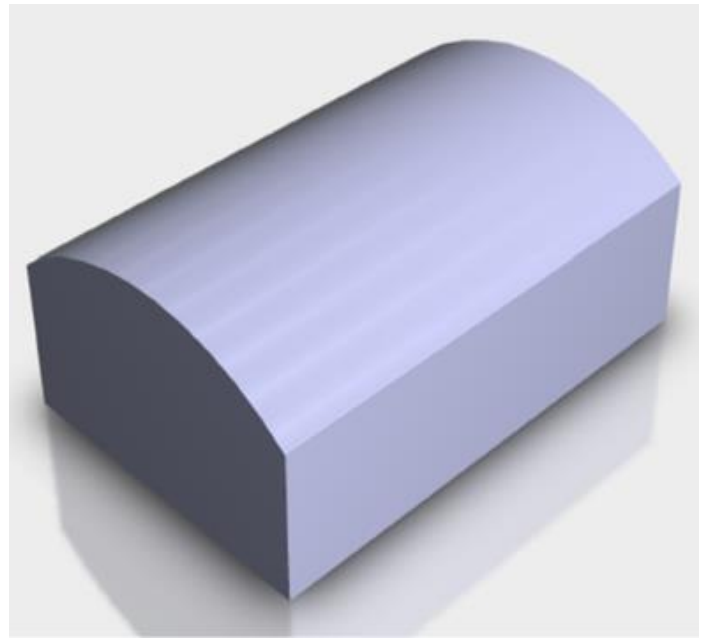

Fig. 4. Dome roof design 


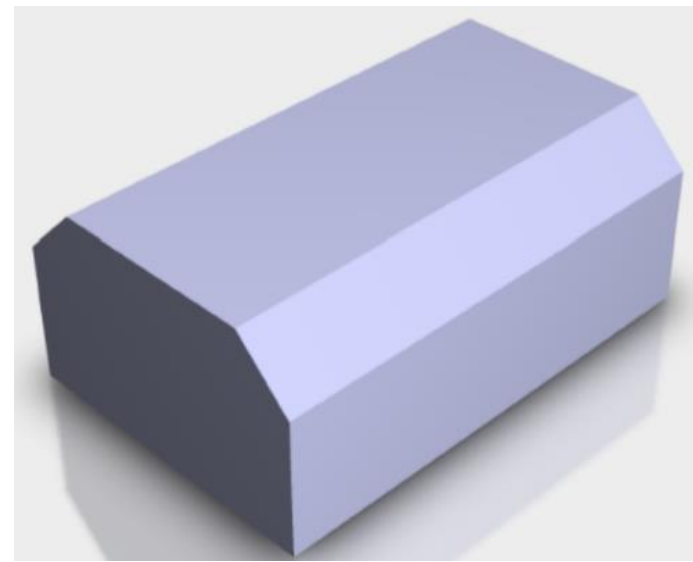

Fig. 5. Trapezoidal roof design

The CAD Model of Solar Greenhouse Dryer for three different shapes was imported to ANSYS Workbench for temperature distribution. The meshing is one of the most important parameters in the analysis of any domain. The mesh size decides the convergence factor. The physics preference set during numerical simulation was CFD, and solver preference was set to FLUENT. The element order of meshing was linear, with default size of $63.286 \mathrm{~mm}$ for all three computational domains. The growth rate of mesh was set on default with growth rate of 1.2, and default maximum size of $126.57 \mathrm{~mm}$ for all three computational domains respectively. The defeature sizing of the mesh was set on default with $0.3164 \mathrm{~mm}$ size for all three computational domains. The capture curvature minimum size was set on default with 0.632 $\mathrm{mm}$ for all three computational domains. The curvature normal angle was set on $18^{\circ}$. The target skewness of all three computational domains was 0.9000 with high smoothing. The smooth transition was set for meshing with transition ratio of 2.72 with maximum 5 layers and a growth rate of 1.2 for all three computational domains. The patch conforming algorithm was used during meshing of domain with element size of $45 \mathrm{~mm}$ and element size was set on global settings for all three computational domains.

In the present research work for all three computational domains, the unstructured tetrahedral mesh was used. The details of meshing for all three domains i.e., number of nodes and number of elements are as follows (Tab. 2).

Tab. 2. Details of meshing

\begin{tabular}{cccc}
\hline Sr. no. & $\begin{array}{c}\text { Shape of } \\
\text { roof }\end{array}$ & No. of nodes & $\begin{array}{c}\text { No. of } \\
\text { elements }\end{array}$ \\
\hline 1 & Triangular & 5735 & 23110 \\
\hline 2 & Dome & 5957 & 24299 \\
\hline 3 & Trapezoidal & 6099 & 25291
\end{tabular}

The details of the meshing of domains are as elaborated in Figures 6 to 8.

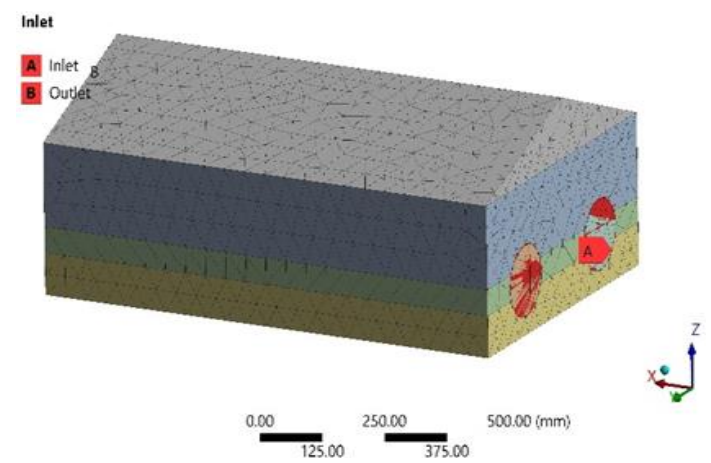

Fig. 6. Meshing of triangular roof domain

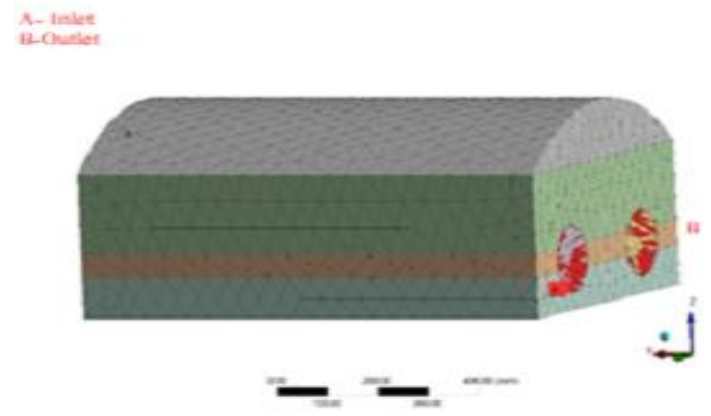

Fig. 7. Meshing of Dome roof domain

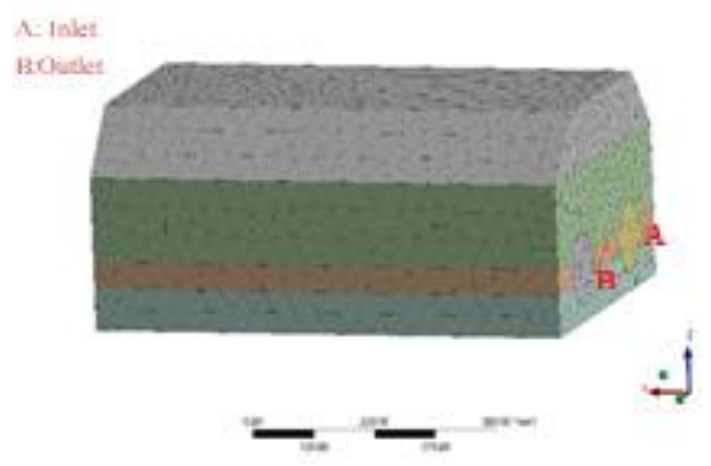

Fig. 8. Meshing of Trapezoidal roof domain

The actual experimental setup was placed in an open atmosphere, where there is ample of solar radiation and wind present in and around the solar dryer. Therefore, to provide same atmosphere in the ANSYS Workbench domain, some assumptions and boundary conditions need to be applied for the numerical simulation. Thus, some assumptions need to be made during numerical simulation for obtaining results. The assumptions made during numerical simulation are as follows. 
1. The walls of dryer are supposed to be covered with a thin polyethene with a thickness of $200 \mu \mathrm{m}$ to absorb direct and diffuse solar radiations.

2. The interior part of the dryer was supposed to be hollow i.e., as in case of actual solar dryer the air is present inside and outside of dryer, in same way the hollow part assumed is supposed to work as an air medium

3. The inside part was assigned as air and it was provided the wind velocity with high and low value at experimental site.

4. Further the inlet and outlet were provided to load and unload the dried product at tray level.

5. The inlet and outlet also serve as the air inlet and outlet passage respectively.

6. The solar irradiation is the power per unit area received from sun at experimental site is used during solar ray tracing.

7. The ground surface of the solar dryer is covered with sand and thin plastic polyethene.

The Solar-Ray Tracing concept was used, the solar ray tracing is the solar ray tracing model is algorithmbased model that uses direct illuminating energy from sun. The heat flux generated has been computed by the algorithm and then sent back to ANSYS for numerical simulation. The coordinates at experimental site are $17.115^{\circ} \mathrm{N}$ and $74.33^{\circ} \mathrm{E}$ i.e., at Bahe Borgaon, DistSangli, Maharashtra, India respectively. The data at the experimental site was evaluated from NASA-Prediction Of Worldwide Energy Resources, from the data available temperature and wind velocity range at the above-given coordinates is as given below in Table 3 .

Tab. 3. Temperature and wind velocity range at given coordinates.

\begin{tabular}{cccc}
\hline Sr. no. & Specifications & $\begin{array}{c}\text { Maximum } \\
\text { value }\end{array}$ & $\begin{array}{c}\text { Minimum } \\
\text { value }\end{array}$ \\
\hline 1 & Temperature, ${ }^{\circ} \mathrm{C}$ & 40.82 & 20.79 \\
\hline 2 & Wind velocity, $\mathrm{m} / \mathrm{s}$ & 7.311 & 5.75 \\
\hline
\end{tabular}

The materials properties used during Numerical Simulation for various parts of the Solar Greenhouse Dryer are as follows (Tab. 4).

Tab. 4. Details of Material Properties

\begin{tabular}{cccc}
\hline $\begin{array}{c}\text { Sr. } \\
\text { no. }\end{array}$ & Properties & $\begin{array}{c}\text { Thin Plastic } \\
\text { Foil }\end{array}$ & Air \\
\hline 1 & Density, kg/m $\mathrm{m}^{3}$ & 1220 & 1.225 \\
\hline 2 & $\begin{array}{c}\text { Specific heat, } \\
\mathrm{J} / \mathrm{kg} \mathrm{K}\end{array}$ & 1.13 & 1005 (@300K) \\
\hline 3 & $\begin{array}{c}\text { Thermal } \\
\text { conductivity, } \\
\mathrm{W} / \mathrm{m} \mathrm{K}\end{array}$ & 0.205 & $27.35\left(@ 40^{\circ} \mathrm{C}\right.$ \\
\hline
\end{tabular}

The boundary conditions are very necessary to get proper results in numerical simulation of Solar Greenhouse Dryer. The material used for the outer domain is a thin plastic foil for a maximum solar gain during direct and diffuse radiation, and inside dryer the assumption of air is done for better results. The inner structure of dryer is considered hollow from the inside as per assumption made, the air acts as a drying media. The actual ideology behind considering the hollow inner structure of dryer is that the air present in the dryer is heated due to solar radiation incident on the dryer and thus the product can be dried effectively with the help of that hot air. The maximum and minimum wind velocity i.e., $7.311 \mathrm{~m} / \mathrm{s}$ and $5.75 \mathrm{~m} / \mathrm{s}$ are assumed during numerical simulation. The airflow assumed during numerical simulation is incompressible, steady, threedimensional. The number of iterations performed is 500. The outer material of the dryer is a thin thin transparent polyethene plastic foil with a thickness of $200 \mu \mathrm{m}$ absorbs direct and diffuse solar radiation. The inner part of the dryer is assumed as the air for optimum results in numerical simulation. The material properties of thin plastic foil and air is given in Table 4 respectively.

\section{RESULTS}

The results obtained during numerical simulation of triangular roof design are as elaborated in Figures 9 to 11.

The results obtained from the numerical simulation of dryer with triangular roof has maximum temperature distribution at the roof surface of $56.36^{\circ} \mathrm{C}$ as the solar radiation incident on the dryer roof is a considered as beam as in solar ray tracing method is used while numerical simulation. The tray area where the inlet and outlet sections are provided has a minimum temperature distribution as the air inlet is continuous in flow, the time required to heat air by solar radiation is more. Thus, the area near tray has minimum temperature distribution of $24^{\circ} \mathrm{C}$ compared to that of roof surface.

The air surrounding the drying tray area has a temperature distribution of $41.7^{\circ} \mathrm{C}$, which will be helpful while drying products effectively. The above triangular structure and the lower rectangular structure of a dryer has a temperature distribution of $30.45^{\circ} \mathrm{C}$, whereas the area above drying tray up to the upper triangular structure has a temperature distribution of $27.14^{\circ} \mathrm{C}$ respectively. The base of the dryer is assumed to be covered with sand and thin polyethene, and the boundary conditions there considered is same as that of thin plastic polyethene. The triangular roof structure has more even temperature distribution. 


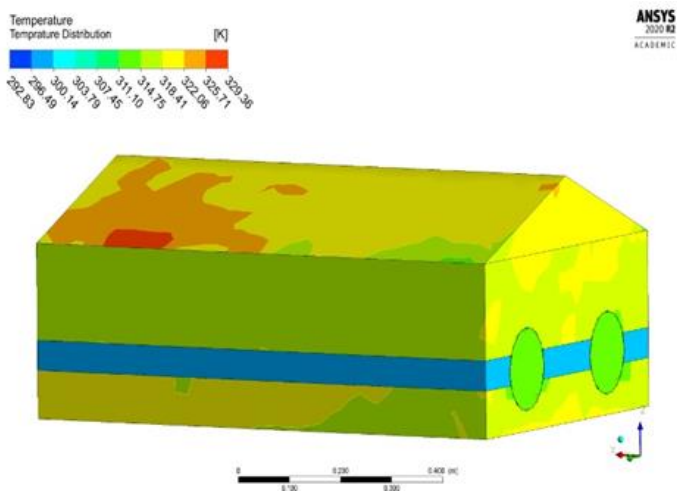

Fig. 9. Temperature distribution profile for triangular roof design

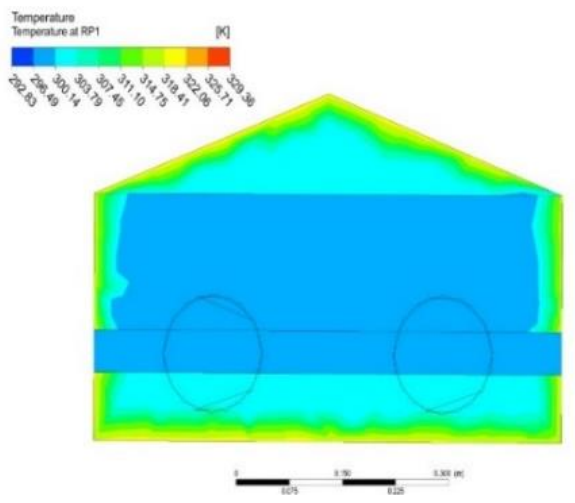

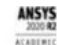

Fig. 10. Side view of temperature distribution profile for triangular roof
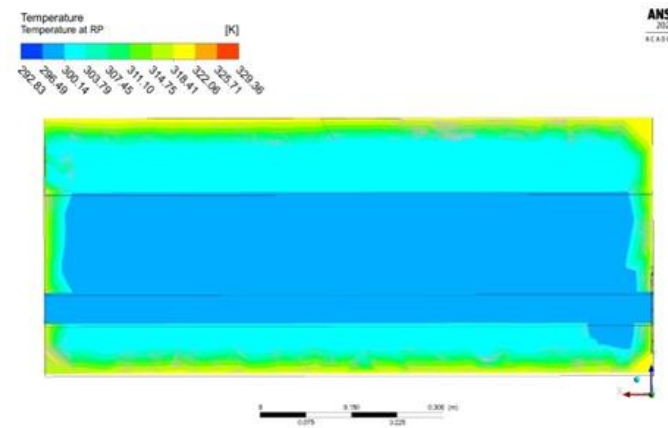

Fig. 11. Side view of temperature distribution profile for triangular roof

The results obtained during numerical simulation of dome-shaped roof design are as elaborated in Figures 12 to 14 .

The results obtained from the numerical simulation of dryer with dome roof shape, has a maximum temperature distribution at roof area of $52.97^{\circ} \mathrm{C}$ as the concept of solar ray tracing has been used while simulating the domain. The solar radiation is formed as a illuminating beam, and thus the solar intensity is focused on the roof surface. The area near the drying tray has a least temperature distribution of $25.51^{\circ} \mathrm{C}$, as the continuous air flows inside the inlet and outlet section surrounding the dryer. The base of the dryer is assumed to be covered with sand and thin polyethene, and the boundary conditions there considered is same as that of thin plastic polyethene.

The results obtained during numerical simulation of trapezoidal roof design are as elaborated in Figures 15 to 17 .
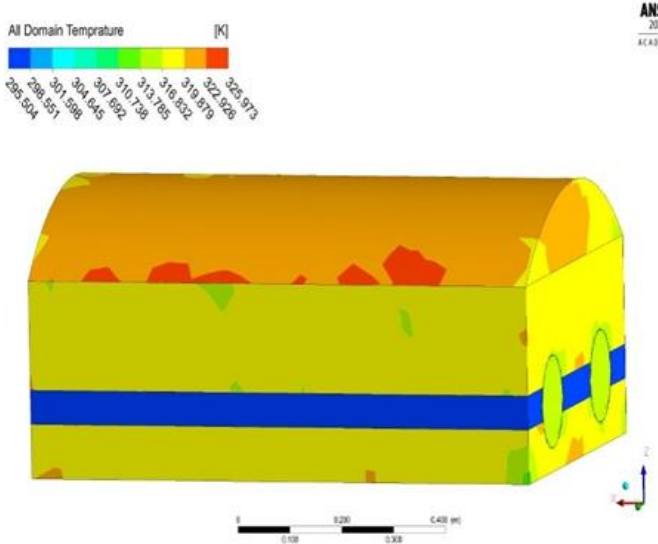

Fig. 12. Temperature distribution profile for dome-shaped roof

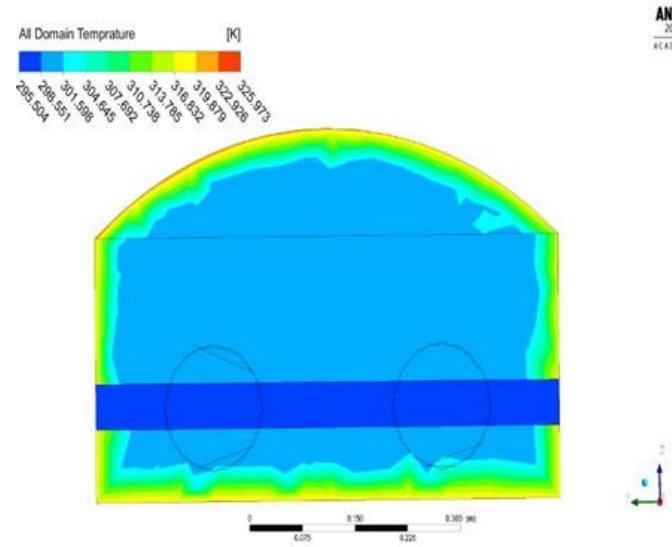

Fig. 13. Side view of temperature distribution profile for dome-shaped roof
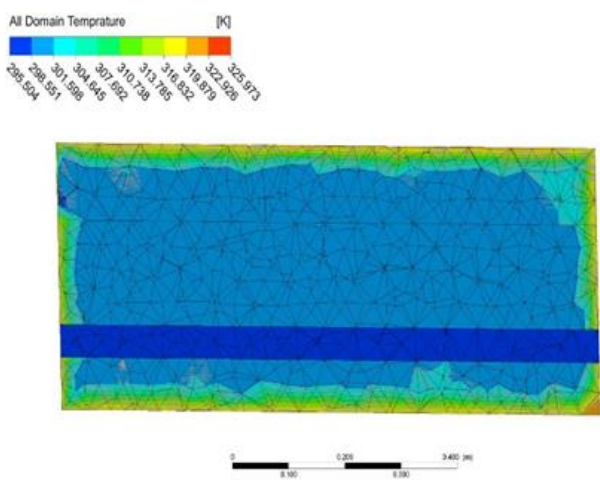

$\stackrel{\dagger}{\leftarrow}$

Fig. 14. Side view of temperature distribution profile for dome-shaped roof 


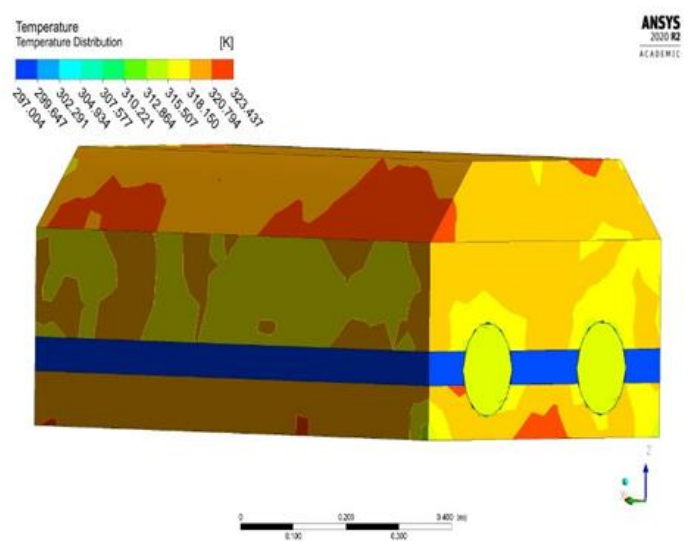

Fig. 15. Temperature distribution profile for trapezoidal roof

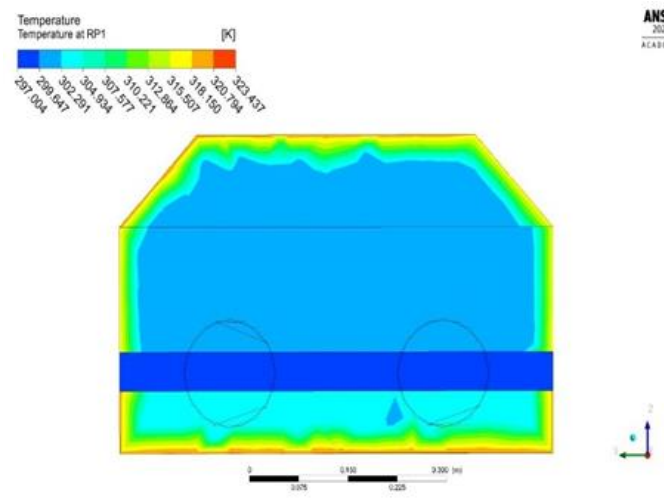

Fig. 16. Side view of temperature distribution profile for trapezoidal roof

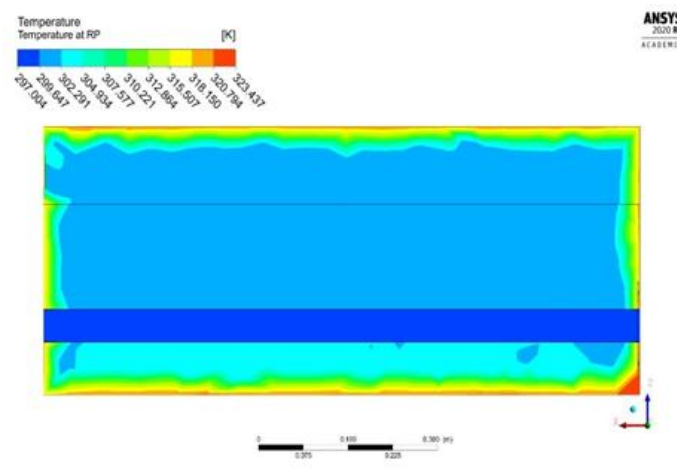

Fig. 17. Side view of temperature distribution profile for trapezoidal roof

The results obtained from the numerical simulation of dryer with trapezoidal roof has a maximum temperature gain at roof surface and at the ground surface of $50.43^{\circ} \mathrm{C}$, as the concept of solar ray tracing is used while simulating the dryer. The temperature distribution profile is not even in trapezoidal roof design as the temperature in the upper section above the drying tray is $26.64^{\circ} \mathrm{C}$.

The temperature distribution in the triangular roof structure is more even as, the temperature increment is seen in upper triangular section and at the base of rectangular section i.e., nearly more than half part of the dryer has a temperature distribution of $30.76^{\circ} \mathrm{C}$ which is very beneficial for drying of products. The other two models do not have even temperature distribution. The dome shaped roof has even temperature distribution of about $28.93^{\circ} \mathrm{C}$ and trapezoidal roof has a even temperature distribution of $29.2^{\circ} \mathrm{C}$, which is lower than triangular roof dryer.

The details of temperature distribution for various roof shapes for the Solar Greenhouse Dryer prototype are as given below in Table 5 .

Tab. 5. Details of numerical result

\begin{tabular}{cccc}
\hline Sr. no. & $\begin{array}{c}\text { Shape of } \\
\text { roof }\end{array}$ & $\begin{array}{c}\text { Maximum } \\
\text { temperature, } \\
{ }^{\circ} \mathrm{C}\end{array}$ & $\begin{array}{c}\text { Minimum } \\
\text { temperature, } \\
{ }^{\circ} \mathrm{C}\end{array}$ \\
\hline 1 & Triangular & 56.37 & 19.83 \\
\hline 2 & Dome & 52.97 & 22.5 \\
\hline 3 & Trapezoidal & 50.4 & 24 \\
\hline
\end{tabular}

Thus, from the results, it is clear that the triangular roof design has a maximum solar gain and temperature distribution of nearly $56.37^{\circ} \mathrm{C}$ respectively. The temperature distribution observed during solar ray tracing of solar greenhouse dryer for three different roof shapes, the more even temperature distribution is observed in triangular roof design respectively. Therefore, for the experimental setup, the triangular roof with minor modifications has been incorporated for drying of agricultural yield.

\section{NO-LOAD TEST}

The no-load test is the test carried out on a dryer to insight the obtained numerical simulation results match the actual experimental setup. The no-load test conducted at experiment set i.e., at Bahe-Borgaon, DistSangli, Maharashtra state, India was conducted from 10 am to $6 \mathrm{pm}$ respectively. The details of the No-Load Test setup for the Solar Greenhouse Dryer are as shown below (Figs. 19, 20).

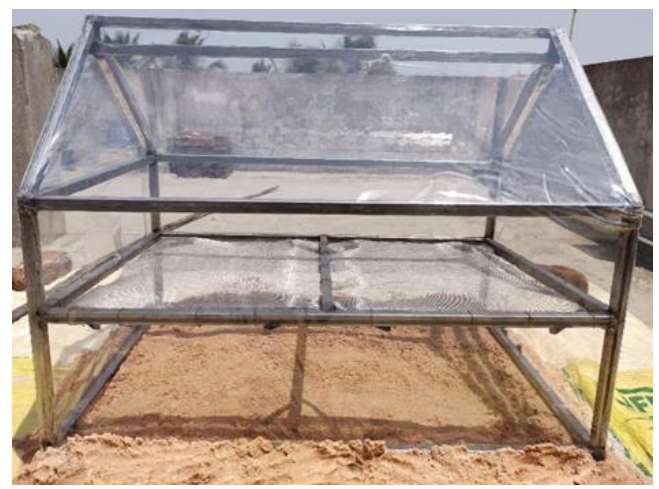

Fig. 18. No Load Test for solar greenhouse dryer 
The details of instruments used during the evaluation of experimental results of SGHD are as follows (Tab. 6).

Tab. 6. Details of instruments used during experimental observations

\begin{tabular}{cccc}
\hline $\begin{array}{c}\text { Sr. } \\
\text { no. }\end{array}$ & $\begin{array}{c}\text { Name of } \\
\text { instument }\end{array}$ & Manufacturer & Details \\
\hline 1 & $\begin{array}{c}\text { Solar Power } \\
\text { Meter }\end{array}$ & $\begin{array}{c}\text { Tenmmars } \\
\text { TM-207 }\end{array}$ & $\begin{array}{c}\text { Measurement } \\
\text { of solar } \\
\text { radiation }\end{array}$ \\
\hline 2 & $\begin{array}{c}\text { Digital } \\
\text { Annemometer }\end{array}$ & Work Zone & $\begin{array}{c}\text { Measurement } \\
\text { of wind } \\
\text { speed. }\end{array}$ \\
\hline 3 & Temperature gun & $\begin{array}{c}\text { Kusum- } \\
\text { Meco IRL- } \\
300\end{array}$ & $\begin{array}{c}\text { Measurement } \\
\text { of } \\
\text { tempearture. }\end{array}$ \\
\hline
\end{tabular}

The details of results obtained from the No-Load Test of the solar greenhouse dryer are presented in Table 7.

Tab. 7. Experimental Observations for No-Load test

\begin{tabular}{cccccc}
\hline Sr. no. & Time & $\begin{array}{c}\text { Wind } \\
\text { speed, } \\
\mathrm{m} / \mathrm{s}\end{array}$ & $\begin{array}{c}\text { Solar } \\
\mathrm{rad}^{\mathrm{n}}, \\
\mathrm{W} / \mathrm{m}^{2}\end{array}$ & $\begin{array}{c}\text { Temp. } \\
(\mathrm{Atm} .) \\
\left({ }^{\circ} \mathrm{C}\right)\end{array}$ & $\begin{array}{c}\text { Temp } \\
(\mathrm{SGHD}) \\
\left({ }^{\circ} \mathrm{C}\right)\end{array}$ \\
\hline 1 & $10: 00 \mathrm{am}$ & 0.45 & 786 & 27 & 41 \\
\hline 2 & $11: 00 \mathrm{am}$ & 0.75 & 938 & 23 & 48 \\
\hline 3 & $12: 00 \mathrm{pm}$ & 0.50 & 980 & 40 & 52 \\
\hline 4 & $1: 00 \mathrm{pm}$ & 0.40 & 1002 & 43 & 53 \\
\hline 5 & $2: 00 \mathrm{pm}$ & 1.50 & 910 & 47 & 58 \\
\hline 6 & $3: 00 \mathrm{pm}$ & 1.65 & 742 & 45 & 53 \\
\hline 7 & $4: 00 \mathrm{pm}$ & 0.80 & 468 & 40 & 40 \\
\hline 8 & $5: 00 \mathrm{pm}$ & 2.34 & 105 & 35 & 36 \\
\hline 9 & $6: 00 \mathrm{pm}$ & 3.39 & 38 & 30 & 32 \\
\hline
\end{tabular}

The no-load test curve for Solar Greenhouse dryer and Open Sun Drying is as shown in Fig. 19.

\section{No Load Test Curve}

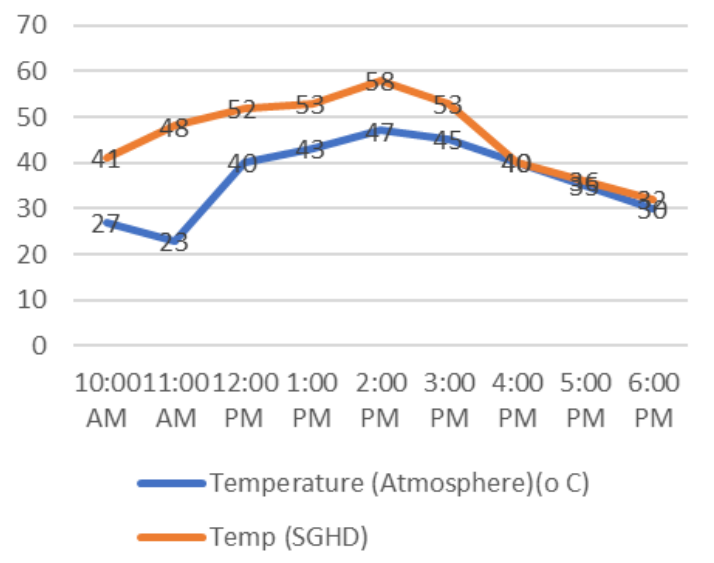

Fig. 19. No-load test curve
From the No-load test curve, it is clear that the maximum gain from Solar Greenhouse Dryer is nearly $58^{\circ} \mathrm{C}$, whereas the numerically simulated model has a maximum temperature gain of $56.37^{\circ} \mathrm{C}$. The open sun drying i.e., atmospheric drying has a maximum gain of $47^{\circ} \mathrm{C}$. The experimental results have convergence with the numerically simulated model of Solar Greenhouse Dryer.

\section{CONCLUSIONS}

The Solar Greenhouse Dryer is an effective way to prevent the agricultural yield from deterioration due to excess growth of micro-organisms. The Solar Greenhouse Dryer provides the optimum temperature that is required for drying agricultural yields with high moisture content. The numerical simulated models of Solar Greenhouse Dryer for various roof designs are analyzed for maximum solar gain i.e., direct and diffuse solar radiation. The Solar Greenhouse Dryer is modeled in CATIA V5 R20 and the CAD model is exported to ANSYS 2020 R20 for solar ray tracing of different roof orientations.

The results obtained from the temperature distribution profile of Greenhouse Dryer's with different roof orientations state that the triangular roof design has a maximum temperature distribution of about $56.37^{\circ} \mathrm{C}$, the dome-shaped roof has a maximum temperature distribution of $52.97^{\circ} \mathrm{C}$, and the trapezoidal roof design has a maximum temperature distribution of $50.4^{\circ} \mathrm{C}$ respectively. Thus, the triangular roof design provides the optimum temperature range for drying of agricultural yield with high moisture content, and hence experimental setup has been manufactured accordingly.

The Solar Greenhouse Dryer is to be designed for rural settings, where ample agricultural yield with high moisture content is available. Another major parameter to be considered while designing a Solar Greenhouse Dryer is the availability of electricity in rural areas. Due to load shedding, the grid electricity cannot be effectively utilized in a rural context. Therefore, the triangular roof design of the Solar Greenhouse Dryer has to be modified to make the design compatible without the use of grid electricity. Thus, an upper vent is provided for a triangular roof design to allow air passage into the dryer. The results of the numerically simulated model converge with the experimental setup of Solar Greenhouse Dryer respectively.

\section{References}

1. S. Vijayan, T. V. Arjunan, Anil Kumar. Fundamentals of Drying. Solar Drying Technology- Concept, Design, Testing and Modeling, Economics and Environment 2017; 3-38

2. Labuza TP, McNally L, GallagherD, Hawkes J, Hurtado F. Stability of intermediate moisture foods. 1. Lipid oxidation. Journal of Food Science1972; 37(1):154-159.

3. Prakash O, Kumar A. Annual performance of modified greenhouse dryer under passive mode in no-load 
conditions. International Journal of Green Energy 2015; 12:1091-1099.

4. Aditya Arvind Yadav, Akshay Vijay Yadav, Jaydeep S Bagi, Pravin A Prabhu. Design of a Solar Modified Greenhouse Prototype. Journal of Science and Technology; 2021; 06(01); 118-125.

5. Rintu Kumar, Vishal Gupta, Rajiv Varshney. Numerical Simulation of Solar Greenhouse Dryer Using Computational Fluid Dynamics. International Journal of Research and Scientific Innovation 2017; 111-115.

6. Zh. S. Akhatov, A. S. Khalimov. Numerical Calculations of Heat Engineering Parameters of a Solar Greenhouse Dryer. Applied Solar Energy2015; 51(2): 26-30.

7. Vivekanandan M, Periasamy K, Babu CD, Selvakumar G, Arivazhagan R. Experimental and CFD investigation of six shapes of solar greenhouse dryer in no-load conditions to identify the ideal shape of dryer. Materials Today: Proceedings. 2020; 1-8.

8. Prakash O, Kumar A, Laguri V. Performance of modified greenhouse dryer with thermal energy storage. Energy Reports 2016; 2:155-162.

9. Kumar A, Tiwari GN. Effect of mass on convective mass transfer coefficient during open sun and greenhouse drying of onion flakes. Journal of Food Engineering 2007; 79:1337-1350.

10. Vishal Gupta, Bhagyashri Dhurve, Abhishek Sharma. Experiment analysis on modified greenhouse dryer in noload conditions. International Journal of Engineering Technology Research \& Management 2017; 2(4): 100105.

\section{Biographical notes}

Biographical notes were not provided. 
